UDК: 821.09(44); 821.133.1.09-1 КЛОДЕЛ П.; 821.133.1.09-1

\title{
ZAPADNI IDEOGRAM I ORIJENTALNI EGZOTICIZAM: POL KLODEL I VIKTOR SEGALEN
}

\author{
ZORAN SKROBANOVIĆ 1 \\ Univerzitet u Beogradu, \\ Filološki fakultet, Katedra za orijentalistiku, \\ Beograd, Srbija
}

Nadahnutost Kinom ima važnu ulogu u književnim delima Pola Klodela i Viktora Segalena. Ta dva francuska stvaraoca predstavljaju svojevrsnu sponu između modernizma i književnih tradicija koje su mu prethodile. U tom kontekstu, Klodelovo i Segalenovo zanimanje za kineske književne forme, jezik i pismo predstavlja nagoveštaj modernističkih preokupacija i eksperimenata u kojima su vidljivi kineski uticaji. Klodel, po uzoru na kinesko pismo, nastoji da ikonizuje simbolički sistem u sopstvenom jeziku stvarajući tako autentične pesničke tvorevine, a Segalen nam predstavlja veoma ličan doživljaj Kine, koji je istovremeno bremenit informativnim sinološkim opservacijama. Uticaj koji su Klodel i Segalen ostvarili svojom stvaralačkom percepcijom Kine bio je dvostruk: $s$ jedne strane, oni su zapadnog čitaoca upoznali s vrednim segmentima kineskog kulturnog nasleđa, ali su istovremeno pokrenuli i čitav niz pitanja u vezi sa ulogom, slobodom i strategijama književnika kao objektivnog tumača drugih kultura.

Ključne reči: Kina, Francuska, ideogram, poezija, egzoticizam, alfabet, sinologija, modernizam.

\section{KINA KAO EVROPSKA INSPIRACIJA}

Kina je dugi niz vekova predstavljala pravi predmet fascinacije za Evropu i njene mislioce. U svom izvanrednom dvotomnom delu naslovljenom Kineska Evropa Rene Etjembl (René Étiemble, 1909-2002) definisao je presudne momente onoga što on naziva "sinizacijom Evrope" (Etiemble 1988: 26) od vremena rimskog carstva do kraja prosvetiteljstva. Evropska recepcija Kine i njene kulture menjala se u različitim periodima zapadne istorije, a Etjembl ih podrobno objašnjava iz perspektive filozofskih i političkih agendi.

1 Kontakt podaci (Email): zoran.skrobanovic@yahoo.com 
Takozvana šinoazerija (od francuskog termina chinoiserie) ili kinoazerija, prisutna je u evropskim umetničkim stilovima još od kraja sedamnaestog veka, to jest od prvih kontakata koji su usledili s pristizanjem artefakata iz Kine preko jezuitskih sinologa i trgovaca. Veoma rano, u Evropi se počelo s proizvodnjom porcelana na kojem su se imitirali kineski motivi, tehničko umeće i kineski karakteri, a u modi su bili predmeti i roba od svile, lakiranog drveta i slično, koji su različitim putevima uvoženi iz Kine. Pomama za kineskim proizvodima i umetnošću ostavila je uticaj na unutrašnju dekoraciju, arhitekturu i uređenje pejzaža, ali je popularnost šinoazerije počela da opada pod uticajem neoklasicizma u umetnosti.

U vremenu koje je usledilo, šira publika, ali i eminentni autori (pred)modernističkog opredeljenja upoznavali su se sa kineskom umetnošću i kulturom preko umetničkih dela, izložbenih eksponata, kao i predmeta u svakodnevnoj upotrebi koji su bili poreklom iz Kine ili su imali kineska obeležja. Galerijski događaji koji su bili ključni za ponovno buđenje interesovanja za Kinu kod Evropljana u drugoj polovini devetnaestog i početkom dvadesetog veka bile su svetske izložbe koje su organizovane u Evropi i Americi, posebno Svetska izložba u Parizu 1867. i 1900. godine, a potom i Izložba kineskog i japanskog slikarstva u Britanskom muzeju (1910-1912). U obema izložbama, na izvestan način, naglašena je dinamika vizuelnog medijuma preko kojih su se Evropljani upoznali s kineskom mišlju, estetikom i pismom. Treba naglasiti da je kineska umetnost u ovom periodu doneta u Evropu i Ameriku kao rezultat imperijalističke politike i čiste krađe, ali je ona istovremeno u očima nadahnutih zapadnih stvaralaca postala sredstvo kineske kulturne moći koje je posmatrače podsticalo da joj se prepuste i pretrpe njen uticaj.

U spletu različitih misaonih uticaja kakvi su sjajni prevodi klasične kineske književnosti francuskih sinologa, popularnost pojedinih nadahnutih prevoda nastalih u devetnaestom veku, kao i percepcija Kine u francuskom kolonijalnom kontekstu, u „Heksagonu“ se početkom prošlog veka rađanovo shvatanjekineskekulture otelotvoreno u inovativnim književnim pristupima jednog broja autora inspirisanih Kinom. U delima tih stvaralaca ne radi se više o površnoj šinoazeriji svojstvenoj dotadašnjim umetničkim predstavljanjima Kine, već je reč o mnogo dubljim književnim impresijama koje je Kina, ali i kinesko pismo izazvalo u umovima stvaralaca nove generacije.

$\mathrm{U}$ tom kontesktu, značajno je pomenuti takozvane pisce francuskog egzoticizma kakvima se mogu smatrati Viktor Segalen (Victor Segalen, 1878-1919) i Pol Klodel (Paul Claudel, 1868-1965) čiji je plodonosni boravak u Kini doveo do ostvarenja čitavog niza književnih projekata. Iako se po svom umetničkom izrazu ne mogu svrstati u stvaraoce modernizma, u njihovim književnim delima susrećemo se sa idiosinkratičnim percepcijama kineskog pisma netipičnim za dotadašnju zapadnu književnu tradiciju. U njihovom pesništvu, poetici i stvaralačkom doživljaju kineskog pisanog sistema uočljiva je preteča onoga na šta u punoj meri nailazimo u zrelom modernističkom izrazu kasnijih autora.

\section{UPOZNAVANJE ISTOKA}

Pol Klodel je pripadao grupi francuskih pisaca-diplomata kakvi su bili Pol Moran (Paul Morand, 188-1976), Žan Žirodu (Jean Giraudoux, 1882-1944) ili Andre Salmon 
(André Salmon, 1881-1969). Tokom svoje briljantne diplomatske karijere, Klodel je bio francuski ambasador u Japanu (1921-1927), kao i povremeni francuski konzul za trgovinu u Šangaju, Handžou, Fudžou i Tjenđinu u periodu od trinaest godina (18951907). Klodel nikada nije savladao kineski ili japanski jezik, ali uspeo je da se profiliše kao jedan od vodećih francuskih poznavalaca istočnih kultura. Pisac je raznorodnih književnih dela kao što su Upoznavanje istoka (Connaissance de l'Est, 1900), Istočnjački ideogrami (Idéogrammes occidentaux, 1926), Male kineske pesme (Petits Poèmes d'après le chinois, 1939) i tako dalje.

U svetlu našeg istraživanja, značajna su Klodelova promišljanja ideograma na koje najpre nailazimo u Upoznavanju Istoka, posebno u njegovoj proslavljenoj proznoj pesmi Religija znaka (Religion du signe). Ova zbirka proznih poema značajna je i zbog činjenice da se smatra nekom vrstom književne karike između francuskog simbolizma i modernizma.

Pre odlaska u Kinu, Klodel je bio tek donekle upoznat sa njenim kulturnim dostignućima: uživao je u popularnoj žaponizeriji i crtežima-estampama Hokusaija (Katsushika Hokusai, 葛飾北斎, 1760-1849) i Utamaroa (Kitagawa Utamaro, 喜多川 歌 麿, 1753-1806), posećivao kineske paviljone na svetskim izložbama u Parizu i naravno, posedovao primerak Knjige od žada Žudit Gotje. ${ }^{2}$

U Upoznavanju Istoka, očigledni su poetski uticaji Malarmea i Remboa, ali i naglašenost "racionalnih postupaka u stvaranju teksta“ i „drugačije estetike", kao i opčinjenost apstraktnom semiotikom novog jezika (Pérez 1995: 21). Predstavljajući kroz zavodljive poetske odlomke sopstveno viđenje kineske realnosti (Banjan /Le banyan/, Bor /Le pin/, Svinja /Le porc/), Klodel se poigrava jezičkim pravilima, leksikom, sintaksom i slikama koje "nisu nezavisne od strukture" (Dethurens 1996: 214). On u kineskom pismu pronalazi inspiraciju za pismo-sliku (écriture-peinture) koje oslobađa poeziju horizontalnih linija i mehaničkog kucanja.

U docnijim teorijskim razmatranjima svojih poetskih tehnika, Klodel zaključuje: „Iznenada sam došao na zapanjujuću pomisao. Pa da, i mi imamo ideograme i naši prirodni jezici su jednako pogodni kao i kineski za stvaranje grafičke reprezentacije objekata" (1944: 81). Tako je Klodel, na pragu onoga što će u svojim delima raditi Gijom Apoliner i Anri Mišo (Henry Micheaux, 1899-1984), došao na ideju o zapadnjačkom ideogramu. On nikada nije insistirao na potpunoj tačnosti svojih analiza etimologije, principa i upotrebe sino-japanskih karaktera, baš kao što se u svom delu Poetska umetnost (Art Poétique, 1907) poigravao etimološkim implikacijama francuskih reči i slikovnim kvalitetima pojedinih slova.

U Religiji znaka, Klodel pravi razliku između romanskih slova koja su u suštini vertikalna i kineskih karaktera koji su u svojoj osnovi horizontalni. Grubo upoznat sa principima kineskog pisma, on zaključuje da „ni u snu ne bismo pomislili da (u kineskom

2 Knjiga od žada (Le livre de jade, 1867) Žudit Gotje (Judith Gautier, 1845-1917) predstavlja zbirku prevoda kineske klasične poezije koja imala presudan značaj za upoznavanje šire francuske, a potom i evropske čitalačke publike s književnom tradicijom Kine. Premda nije savršeno vladala kineskim jezikom, prevodi Gotjeove prenose važne teme iz kineske poetske tradicije i na trenutke pokazuju impresivnu vernost duhu izvornika. Iako se često odlučuje da prilagodi kineski stih inovativnoj ritmičnoj prozi, njene prerade zadržavaju emotivnu uzdržanost i slikovitu evokativnost originala, uspešno ostvarujući stilske kvalitete koji su korespondirali sa onovremenim čitalačkim ukusom, ali i poetskim zahtevima narednih razdoblja. 
karakteru) horizontalne linije, na primer, ukazuju na vrste; vertikalne na pojedinačno; oble na grupu obeležja i energija koje svojim raznovrsnim pokretima svemu daju smisao..." (2004: 26).

Kineski karakter ukazuje na "šematizovano bivstvovanje, skribovanu osobu", nepokretan je i sintetičan, dok su slova „po prirodi analitična, pri čemu je svaka reč koju konstituišu uzastopni izraz potvrda koje su izrekle oči i glas" (Claudel 2004: 89). Osnovne tri suprotnosti na kojima počiva odnos između zapadnjačkog ideograma i kineskog karaktera su analitično - sintetično, akcija i pokret spram nepokretnosti i vertikalno naspram horizontalnog.

Sve ove suprotnosti mogle bi se sažeti u jedan osnovni kontrast između alfabeta i kineskog pisma koji nam sugeriše Klodel: jedinstvo ili monolitnost kineskih karaktera i deljivost zapadnjačkih slova. To je na izvestan način, upravo suprotno od onih premisa od kojih će, deceniju nakon njega, nadahnut Fenolozinim (Ernest Fenollosa, 1853-1908) teorijama, poći Ezra Paund (Ezra Pound, 1885-1972) u svom osmišljavanju imažizma i vorticizma. Tamo gde je Paund video asocijativno objedinjene pojedinosti koje sačinjavaju kineske karaktere, Klodel vidi nedeljivu celinu. Jasno je da je pravi ekvivalent Klodelovom alfabetskom doživljaju kineskog karaktera u stvari reč, a ne slovo, to jest da je njegov „"mimologizam u suštini leksički“" (Genette 1995: 269).

U delima koja su nastala kasnije, kao što je zbirka Stotinu izraza za lepezu (Cent Phrases pour éventails) koja se danas smatra "haikuom visokog modernizma" (Eysteinsson, Liska 2007: 705), Klodel će u svojim poemama pokušati i tipografskim rešenjima i kineskim karakterima da sledi estetiku haikua. U jednom od tekstova u vezi sa ovom zbirkom koji je pronađen u Klodelovoj zaostavštini i naknadno preveden, on o svom poetskom postupku kaže:

Samo pisanje igra veliku ulogu, jer u francuskom, kao ni u kineskom, spoljašnja forma slova nije strana izražavanju ideje. Hiljade volšebnih namera skriveno je u kaligrafiji četke samog pisca.

Ono što se pokušava postići rasporedom stihova i reči, umetanjem belina, odgađanjem u praznini bezglasnih suglasnika, znakovima i akcentima, saradnjom između meditacije i izraza, zvukom, glasom, sećanjem, pisanjem i mišlju, jeste da se na taj način otkrije intelektualna vibracija svake reči ili suštinskog dela svake reči onom čitaocu koji je dovoljno strpljiv da se posveti svakoj pesmi, jednoj za drugom, polako, kao kad se ispija šolja vrelog čaja. (Claudel 1992: 8).

Klodel se, dakle, u svojoj poetskoj reprezentaciji i kreiranju pesničkih slika poigrava slikovnim aspektima i karakteristikama pojedinih slova u alfabetskom pismu, prostornim i asocijativnim efektom vokala i akcenata u francuskom jeziku, i nizovima slova u rečima sa ideogramskim karakteristikama. S druge strane, kineski karakteri koji prethode pesmama služe kao "naslov, derivacija ili uzvik" (Claudel 1992: 12).

3 Naziv potiče od japanske skraćenice za poetski žanr povezanih stihova ili hankai no renga (俳諧の連歌), koji se pojavio u Japanu u XVI veku. Iako vodi poreklo od starijih poteskih formi, bio je znatno slobodniji u pogledu formalnih konvencija koje su nametali raniji žanrovi, a pod tim pojmom podrazumevaju se mnogi podžanrovi kao što su haiku, haibun, haiga i tako dalje. 

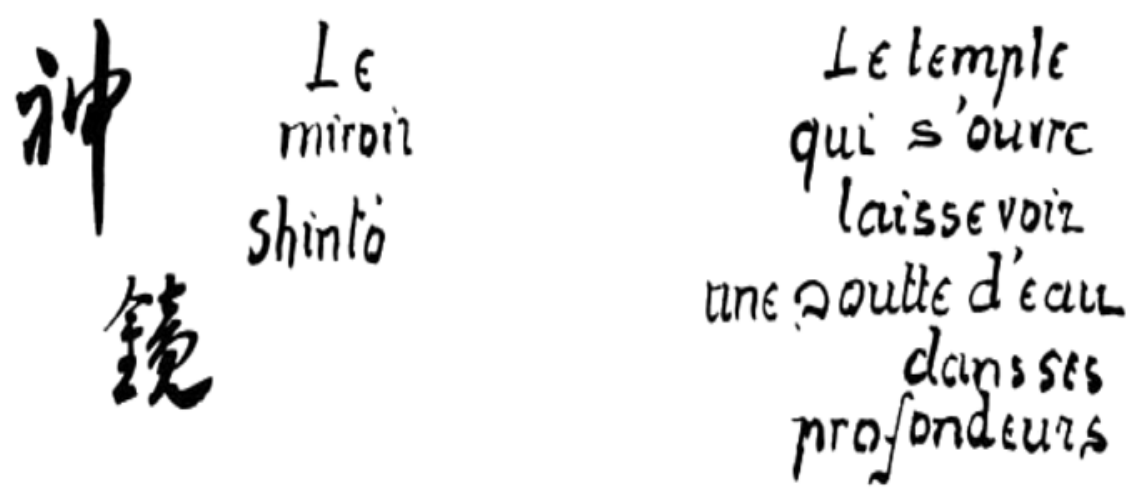

Klodelova pesma Šintoističko ogledalo iz zbirke Stotinu izraza za lepezu, čiji tekst glasi: „Hram koji se otvara daje da vidimo jednu kapljicu vode u dubinama“" (Klodel 2002: 42), sa uvodnim kineskim karakterima 神 (šen/shen/-duh; božanstvo) i 镜 (đing /jing/ogledalo) koje je napisao Klodelov prijatelj Ikuma Arišima (Ikuma Arishima/有島生馬/).

Iako povremeno grafički struktuira svoje poeme u više pravaca, sa vizuelnim diskontuitetima i podelama, za razliku od Apolinerovih kaligrama, Klodelove forme nisu mimetičke, pre bi se moglo reći da su afektivno-izražajne po uzoru na japanske haikue, ili da njegove „pesme leže negde između različitih jezika i pisanih sistema kao samostalne nove kreacije" (Hokenson 2004: 238). Njegova upotreba kineskih karaktera, pre bi se mogla uporediti sa ulogom koji oni imaju u Pevanjima (The Cantos) Ezre Paunda. Oni ne samo da ostvaruju "grafički smisao" (Klodel 2002: 50) Klodelove zbirke, već podsećaju na Paundova nastojanja da ikoničnošću kineskih karaktera svojim Pevanjima ulije dinamičnost i vizuelnu sugestivnost, ali i da u njima sažme, kristalizuje značenje svojim ideogramskim poetskim skupovima.

Iako se služi kineskim karakterima kao ikoničkim pomagalom u sopstvenoj poeziji, Klodel je u svojoj poetskoj kompoziciji više okrenut tradiciji japanske tradicionalne poezije kao što je haiku ili starijoj kineskoj preteči japanskih pesničkih žanrova kakvi su recimo isprekidani stihovi (绝句) koji su na popularnosti dobili za vreme dinastije Tang (唐朝, 618-907). Isprekidani stihovi predstavljaju poetski oblik sa po četiri stiha od pet ili sedam karaktera i u njemu su definisane gotovo sve značajnije osobenosti kineske klasične poezije: kratkoća, pomno osmišljeni asocijativni nizovi, skrivena i neizrečena značenja, neupadljivost pesničkog „,ja“, ali i nedeterminisanost poetskog teksta. Za treći stih se govorilo da ga je najteže napisati, pa su mnogi pesnici počinjali s pisanjem upravo trećeg stiha, a četvrti stih je trebalo da kod čitaoca izazove iznenađenje, ili objavu.

Ne čudi što su upravo neki od prevoda pesničkih oblika iz dinastije Tang, kakvi su isprekidani stihovi, predstavljali ishodište modernističkih poetskih tendencija na Zapadu, jer su svojom tematskom opredeljenošću, pesničkim doživljajem stvarnosti, senzibilitetom i pristupom drevni kineski pesnici ovog razdoblja bili neobično „moderni". U svojim promišljanjima razlika između zapadnog i kineskog pisma, Klodel, usled nedovoljnog poznavanja pisanog kineskog jezika, nije dublje analizirao 
osobenosti i načela kineskih karaktera. Zanimale su ga „ideogramske“ mogućnosti alfabeta i vizuelne sugestije koje može da postigne sopstvenim jezikom.

Ipak, veštom grafičkom primenom kineskih karaktera integrisanih u njegove pesničke oblike inspirisane japanskom i kineskom klasičnom književnom poetikom, Klodel vešto uočava organsku vezu koja postoji između pesme i kaligrafski razigranih kineskih pismena, a koja je karakteristična za kinesku klasičnu poeziju. Njegovi pokušaji ikonizacije simboličkog sistema sopstvenog jezika novom prostornom organizacijom, obogaćeni su i višeznačnim prisustvom kineskih karaktera nastalih pod rasplesanom kaligrafskom četkicom njegovih japanskih prijatelja. Kineskim prisustvom u svojoj poeziji, Klodel je nadahnuo jednog drugog francuskog umetnika, koji je u svojim proučavanjima Kine bio mnogo temeljniji.

\section{PESNIČKA ARHEOLOGIJA}

Viktor Segalen se sa Klodelom prvi put sreo u Tjenđinu 1909. godine odmah po svom dolasku u Kinu u kojoj će provesti pet godina. Samo jednu godinu pre toga, Segalen je, posle lutanja Pacifikom, nadahnut upravo Klodelovim Upoznavanjem Istoka u pariskoj Školi za orijentalne jezike uspešno završio jednogodišnji kurs kineskog jezika. Segalena je zapanjila činjenica da njegov idol, po sopstvenom priznanju, nije znao ni reč kineskog jezika, kao i da se u svojim promišljanjima kineske misli, pisma i umetnosti, uglavnom oslanjao na postojeće francuske prevode.

Segalen se, sa svoje strane, ozbiljno prihvatio uloge budućeg sinologa, koristeći svoj boravak u Kini za čitav niz putovanja i proučavanja koja su rezultirala velikim brojem dela (od kojih su mnoga tek posthumno objavljena) kao što su putopisi Cigla $i$ crep: dve novele (Briques et tuiles, 1975), Sinovi Neba (Fils du Ciel, 1985) i Rene Lej (René Leys, 1922), zbirke pesama Stele (Stèles, 1912), Slike (Peintures, 1916), Bekstvo (Equipée, 1929), Ode (Odes, 1963) i Tibet (Thibet, 1979), kao i raznovrsni arheološki zapisi.

$\mathrm{U}$ pogledu Segalenove percepcije i upotrebe kineskog pisma, Stele i Slike predstavljaju najreprezentativnija dela u njegovom književnom opusu. Svojim Stelama - 古今碑錄 (Epitafi u kamenu od davnina do danas), Segalen je osmislio novi žanr pesamastêla, kao imitaciju natpisa u kamenu na koje je naišao u Kini i prevodima kineske klasične književnosti. U ovim delima, do punog izražaja dolazi ono što karakteriše Segalena još u njegovim ranijim ostvarenjima nastalim kao posledica putovanja po francuskom kolonijalnom prostoru na Pacifiku, a što neki savremeni kritičari nazivaju „egzotražnjom" (Ha 2000: 21).

Rezultat Segalenovog nadahnuća Kinom je lingvistički i kulturološki hibrid u kojem kinesko pismo ima značajnu ulogu. Zbirka je podeljena na stele okrenute ka četiri strane sveta, a ova podela je najverovatnije inspirisana dodatkom u izdanju Istorijskih zapisa (史记) Sime Ćijena (司马迁, 145-86 p.n.e.) u prevodu Eduarda Šavanea (Edouard Chavannes, 1865-1918), Memoires historiques (Pariz, 1895-1905) u kojoj se govori 0 epitafu prvog kineskog cara Ćin Šihuanga (秦始皇, 259-210 p.n.e.) ugraviranoj na četiri strane nadgrobnog kamena (Segalen 2007: 1).

Inspiraciju za svoje imitacije, slobodne prevode i nadahnute kreacije kineskih epitafa, Segalen pronalazi u materijalima do kojih je došao na svojim putovanjima, ali 
i delima i prevodima eminentnih francuskih sinologa kao što su Hrišćanski natpisi u kamenu iz Sian-fua (La Stele chretienne de Si-ngan-fou, 1902) Anrija Avrea (Henri Havret, 1848-1901), Kuvrijerovog Čou Kinga - kineski anali (Chou King: Les Annales de la Chine, 1897) i Knjige obreda (Livre des rites, 1899), Petijonovih (Corentin Pétillon, 1810-1861) Književnih aluzija (Allusions litteraires, 1895) itd.

Segalenu citati, natpisi ili idiomi na kineskom služe kao uvodi ili srž proznih pesama koje predstavljaju slobodne prevode, interpretacije, rekreirane delove izvornika ili nadahnuće za samostalnu pesničku tvorevinu. On se istovremeno poigrava različitim kaligrafskim punktuacijama teksta istražujući nove teritorije u dotadašnjoj francuskoj poeziji. Za razliku od Klodela, u delovima teksta ispisanim na kineskom jeziku i integrisanim u Segalenova pesnička ostvarenja, prepoznaje se sinološko bogatstvo informacija, aluzija i referenci na kinesku kulturnu i književnu istoriju. S druge strane, kineske reference su Segalenove smernice u građenju sopstvene umetničke stvarnosti. Evo ilustrativnog primera postupka kojima se Segalen služi prilikom upotrebe delova teksta ispisanih kineskim karakterima.

U Segalenovoj pesmi "Ogledala" (Miroirs) iz zbirke Stele, najpre je vertikalno ispisano na kineskom:

\section{LJUDI KORISTE BAKAR KAO OGLEDALO/ LJUDI KORISTE PROŠLOST KAO OGLEDALO/ LJUDI KORISTE LJUDE KAO OGLEDALO.}

Zatim sledi deo pesme na francuskom jeziku:

\section{Ogledala}

Cai Ju se ogleda u uglačanom srebru da popravi svoje crne trake

i perle na svojim trakama.

Ako je ruž prebled za njene oči, ili belo ulje presjajno na njenim obrazima, ogledalo je s osmehom opominje.

Savetnik se divi sebi u istoriji, svetla vaza u kojoj je sve jasno: marševi vojski, izreke Mudraca, premetanja sazvežđa.

Odraz koji odatle prima rukovodi njegovim postupcima.

Nemam ni trake, ni perle, ni velika dela koja moram obaviti. Da bih uredio svoj usamljenički život, proučavam se isključivo u svom svakodnevnom prijatelju.

Njegovo lice - bolje od svakog srebra i drevnih pripovesti - pokazuje mi moje vrline u svakom trenutku (Segalen 2007: 127).

Segalen se u uvodnom kineskom tekstu poslužio anegdotom o caru dinastije Tang, Tajzungu (太宗, 599-649), koju je preuzeo iz Istorijskih tekstova (Textes historiques, 1903-1905) Leona Vigera (Léon Wieger, 1856-1933) u kojoj se kaže da je car nakon smrti svog ministra i omiljenog savetnika Vej Dženga (魏徵, 580-643) rekao ostalim velikodostojnicima: „Ljudi se ogledaju u ogledalu da bi se doterivali; u primerima iz drevne prošlosti da bi prosudili jesu li vredni pohvale ili pokude; i u mišljenju svojih savremenika da bi videli jesu li omiljeni ili ne. Vej Dženg mi je pružao sve tri vrste usluga. S njim sam izgubio svoje ogledalo" (Wieger 1905: 1561). 
Kineski tekst nije preveden, jer se Segalen služi kineskim karakterima kao pismom egzotičnim za francuskog čitaoca, otvarajući problematiku onoga što je Kristjan Dume nazvao „sinološkim pitanjem" (1992: 15), jer se takvim pristupom zapadni čitalac lišava potpunog razumevanja teksta. Jedini način da se u potpunosti obuhvate bezbrojne književne i istorijske reference jeste da je čitalac „bilingvalan i... dovoljno upućen u kinesku kulturu" (Hsieh 1988: 10), u protivnom, delovi teksta na kineskom jeziku predstavljaju samo dekorativnu barijeru.

Šezdeset i četiri stele (broj heksagrama u kineskoj Knjizi promena) u Segalenovom imaginarnom muzeju, predstavljaju istraživanje kulturoloških i epistemoloških prepreka u sagledavanju drugačijeg, nudeći rešenje na čisto estetskom nivou. Na (upućenom) čitaocu je da odluči da li su u pitanju prevodi, pseudo-prevodi ili prevodi „nepostojećeg originala“ u kojima Segalen stvara svojevrsnu „paralaksu ili međujezik" (Segalen 2007: 7) kroz krhki susret dva jezička i semiotička sistema.

Za Segalena postoje dva načina na koja Kina može biti vaskrsnuta. Pre svega arheološkim istraživanjima koja ce ukazati na velika kulturna dostignuća carstva koje se u vreme Segalenovog dolaska proživljava teške trenutke. Segalen je autor opsežnih dela iz oblasti arheologije kakvo je Velike statue u Kini (La Grande Statuaire chinoise, 1972), a i sam je učestvovao u mnoštvu arheoloških poduhvata. Drugi način je oživljavanje Kine umetnošću, a evo kako Segalen tumači te delove kineske stvarnosti koju nam on književno predstavlja:

Nije važno reći šta ja mislim o Kinezima (uistinu, ja o njima uopšte nemam mišljenje), već kako ih ja zamišljam... u stvarnom i živom obliku koji je van svake realnosti, a to je u umetničkom delu. (Forsdick 2000: 147).

Takve strategije u prezentovanju kineske misli i kulture svedoče o tome da epitafi nisu slučajno poslužili Segalenu kao inspiracija za prvu zbirku pesama. On, na sebi svojstven način, kao da pokušava da mumifikuje celo jedno živo društvo. Takav pristup sasvim se uklapa u ono što Arif Dirlik naziva kulturološkim impulsom orijentalističke epistemologije koja de-socijalizacijom i deistorizacijom kultura, istovremeno pretvara "orijentalna" društva u predmete divljenja i fosilizovane relikte kojima se pridaju atributi ahistorične prošlosti (1997: 106).

Zbog toga mnogi kritičari Segalenov pristup često upoređuju sa Paundovim Kitajem (Cathay, 1914). Ali, Paundove imaginarne projekcije kineske drevnosti, pre svega su motivisane čitalačkim doživljajem koji on na taj način želi da proizvede. U Segalenovom slučaju, u pitanju je protivurečna poetika koja istovremeno crpe inspiraciju iz kolonijalnih tumačenja sveta, ali im se i snažno suprotstavlja. Jer, svojim poetičkim insistiranjem na dvosmislenosti i nerazrešivim razlikama, Segalen se u svojim tumačenjima Kine udaljava od egzoticizma. Ono što je strano, za Segalena nije privlačno zbog svojih estetskih kvaliteta, već zbog toga što „ร̌okom raspolućuje (pesničko) ja na višestruka sopstva" (Healey 2003: 48).

$\mathrm{Na}$ taj način, Segalen u svojim delima razvija idiosinkratičnu dijalektiku putopisca u kojoj mu Kina služi pre svega da kroz recepciju elemenata "drugačijeg" otkrije drugog sebe. Govoreći o nastanku francuskog modernizma, Hujsen (Andreas Huyssen) primećuje da je „modernost za Francuze pre svega, mada ne i jedino, estetsko pitanje 
vezano za energije koje se oslobađaju namernom destrukcijom jezika i drugih oblika izražavanja" (1986: 203).

Spoznaja o raspolućenosti sopstvene ličnosti predstavlja jedan od prvih koraka ka svesti o varljivosti jezika i nemogućnosti mimezisa. Tako je Segalen još na samom početku veka smelo otvorio vrata modernističkoj i književnoj analizi pesničkog sopstva razapetog između stvarnosti i imaginacije u njegovom doživljaju života. Isto tako, značenjski bremenitim sinološkim opservacijama koje je protkao kroz svoju poeziju, Segalen je anticipirao obuhvatnije tumačenje elemenata kineske kulture na koje kasnije nailazimo u delima velikih stvaralaca modernizma.

\section{LITERATURA}

Claudel, P. 1944. Idéogrammes occidentaux, texte composé \& manuscrit par Guido Colucci. Paris: A l'Enseigne de la Trireme.

Claudel, P. 1992. A Hundred Movements for a Fan, translated from the French and with an introduction by A. Harvey and I. Watson. London: Quartet Books.

Claudel, P. 2004. Knowing the East, trans. by J. Lawler. Princeton, NJ: Princeton UP.

Dethurens, P. 2003. Claudel et l'avènement de la modernité. Paris: Presses universitaires de Franche-Comté.

Dirlik, A. 1997. The Postcolonial Aura: Third World Criticism in the Age of Global Capitalism. Boulder, C0: Westview Press.

Doumet, C. 1992. Le Rituel du Livre. Paris: Hachette.

Etiemble, R. 1988/89. L'Europe chinoise. Vol.1-2. Paris: Gallimard.

Eysteinsson A. and V. Liska. 2007. Modernism, vol. 1. Amsterdam/Philadelphia: John Benjamins.

Forsdick, C. 2000. Victor Segalen and the Aesthetics of Diversity:Journeys between Cultures. Oxford: Oxford UP.

Genette, G. 1995. Mimologics. Lincoln: University of Nebraska Press.

$\mathrm{Ha}$, M-P. 2000. Figuring the East, Segalen, Malraux, Duras, and Barthes. Albany: State University of New York Press.

Healey, K. J. 2003. Modernism Travels: French Detours 1900-1930. Lincoln and London: University of Nebraska Press.

Hokenson, J. 2004. Japan, France, and East-West aesthetics: French literature, 1867-2000. Madison and Teaneck: Fairleigh Dickinson University Press.

Hsieh, Y. Y. 1988. Victor Segalen's Literary Encounter with China. Toronto: University of Toronto Press.

Huyssen, A. 1986. After the Great Divide: Modernism, Mass Culture, Postmodernism. Bloomington: Indiana University Press.

Klodel, P. 2002. Stotinu rečenica za lepeze, prevod i pogovor K. Mićević. Niš: Prosveta.

Pérez, C-P. 1995. Le défini et l'inépuisable - Essai sur 'Connaissance de l'Est' de Paul Claudel.

Paris: Presses universitaires de Franche-Comté.

Segalen, V. 2007. Stèles, translated, edited, and annotated by T. Billings and C. Bush, vol. 2. Middletown: Wesleyan UP.

Wieger, L. 1903-1905. Textes historiques. Hien Hien, China:Imprimerie de la Mission Catholique. 


\section{SUMMARY}

\section{WESTERN IDEOGRAM AND ORIENTAL EXOTICISM: PAUL CLAUDEL AND VICTOR SEGALEN}

China as inspiration plays an important role in the literary work of Paul Claudel and Victor Segalen. The two French authors may be regarded as a missing link between Modernism and the literary traditions that preceded it. In this context, Claudel's and Segalen'sinterestin Chinese literary forms, languageandscriptrepresentsananticipation of the later modernist preoccupations and experiments based on Chinese influences. Taking Chinese script as a role-model, Claudel attempts to iconize the symbolic system in his own language, thus creating new and authentic poetic forms, whereas Segalen introduces a very personal perception of China enriched with informative sinological observations. With their creative perception of China, both Claudel and Segalen succeeded in exerting a double influence: on one hand, they acquainted the Western reader with various valuable segments of Chinese cultural traditions, and on the other, they also provoked a series of questions concerning the role, freedom and strategies of a writer as an objective interpreter of other cultures.

KEYWORDS: China, France, ideogram, poetry, egzoticism, alphabet, sinology, Modernism.

(Originalan naučni rad primljen 29.11.2010; ispravljen 05.08.2011;

prihvaćen 01.12.2011) 